fluid in this case was secreted into the peritoneal cavity. The amount remored is not given, but as much as 16 and 18 pints were withdrawn at a time, so that the total quantity might possibly be greater than in the case now recorded. This patient also "ate, slept, and looked well" after many tapp ings. Dr. Pye-Smith stated that he should have recommended early operative interference more urgently than he tid, because removal of a primary papilloma is sometimes followed by shrivelling of the secondary growth and a complete cure.

The case now related shows that sometimes an orarian tumour causes death simply from exlaustion and pressure. The enormous appetite of the patient was an index of the nourishment required by the growth, and it was only by constantly removing the pressure that the patient could be kept alive. There can be no reasonable doubt that she could have been easily and completely cured if an opera. tion had been performed as soon as the cyst was discovered. It is. clear that as late as 1893 some surgenns did not recognize the importance of early interference in these cases.

Transactions of the PJFFRJNCF

\title{
A METHOD OF SKIN-GRAFTING.
}

$$
\text { BY }
$$

SAMUEL S.MUEL, I.D., Ch.B., M.R.C.S.ENG., LATE Captain R.A.M.C.

THE operation of skin-grafting, usually regarded as a trivial and simple procedure, is not always attended with the success that one would expect. During the war, when skin-grafting was so frequently employed, faulty technique, especially the omission of details of procedure, often led to a failure of the operation. The following method which I adopted gave invariably good results.

The accompanying diagram is almost self-explanatory aud calls for very little description. 'I'the grafts and area

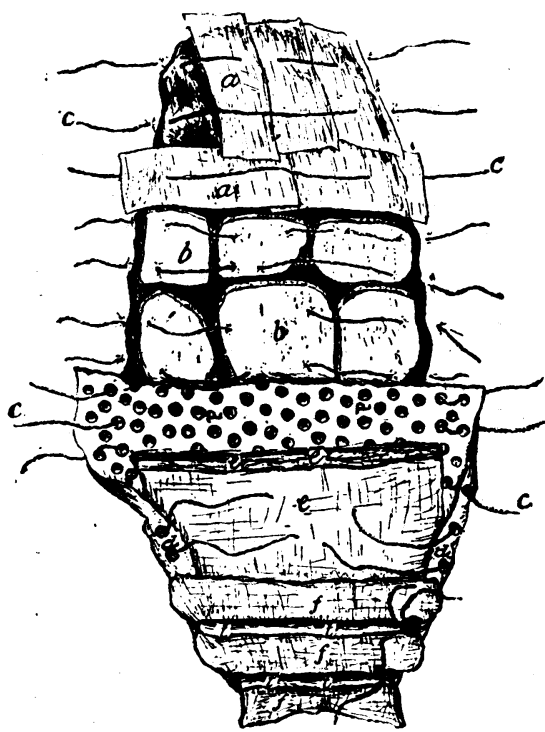

Fig. 1.-a. Thiersch's grafts ; $\dot{v}$, small Wolfe grafts ; $c$, silk threads: $d$, protective; $e$, dee läer of aseptic dressing: $t$, rubber tubing.

sterilized pro-

tective (preferably the transparent variety which is used in America for watching the progress of wounds-the perforations being easily made with the punch used for making holes in Carrel-Dakin tubes), which is then anchored in position as per diagram. On top of the protective is then placed the thick layer of sterile gauze damp with the physiological saline or artificial serum, and then a final over-all dressing consisting usually of a thin layer of dry sterile gauze. The silk threads are then utilized, as the diagram shows, for anchoring all the dressings, the silk being finally threaded through thin rubber tubing aud then knotted on the tubing to prevent cutting through. The knots are tied so that they can be easily undone, and the ends of the silk threads are left long. The whole of the operation area is then covered with a layer of wool and the usual bandaging is applied.
By this method the grafts can be easily and frequently fed, after removing the bandage aud wool, by squeezinu the artificial serum or saline from a swab on to the silk threads between the dressings and the skin, or additionally, by undoing the knotted threads and taking out and replacing the damp thick layer of gauze: The silk threads not only carry the feed, but act as in the operation for lymphangeioplasty and drain away the discharge which forms round the granulations. The amount of the discharge also is lessened by the frequency and simplicity with which the feed can be given. The great advantase of this method is that it is not necessary to disturb the grafts and there is little risk of doing so as with the old methods when the dressing is changed on the third or fourth day. A change of new sterile protective is also unnecessary. Curling and retraction of grafts does not so readily occur and healing is accomplished more certainly and more quickly. The anchoring of the grafts and the dressings is also beneficial in providing the means for applying firm gauze pressure, which is so essential for ensuring success, and for keeping grafts and dressings in position in cavities and hollow surfaces and over convex areas such as the shoulder, breast, and ischium. Grafting over the latter area, previous to the adoption of this new method, was rarcly successful because of the difficulty of kceping the grafts in position, and of kceping clean the parts, which often become soiled by the dressing shifting to the anal area. The use of splints, strapping, and the application of collodion is thus also done away with. When the trans. parent variety of protective is used the state and progress of the grafts can be watched each time a new feed is given when the thick layer of damp gauze is replaced by a fresh one.

'The only disadvantage of this method is the little extra time involved in performing the operation. Tilis naturally becomes less and less with practice, and is readily compensated for by the greater percentage of süccessful cases.

The method adopted cau thus be briefly stated as consisting of the principle of the application of the method of lymphangeioplasty combined with that of auchored dressings.

\section{EIGHTY-NINTH ANNUAL MEETING} OF THE

\section{避itisly Ettediral Aszoriation.}

Held at Nevecastle.on-Tyne, July; 19:1.

SECTION OF SURGERY.

Professor. J. Rutherford Monison, D.C.L., LL.D., F.R.C.S., President.

\section{DISCUSSION ON COMPOUND FRACTURES OF THE THIGH AND LEG.}

\section{OPENING PAPER}

By

Nacgnton Dunv, M.A., M.B., Ch.B.Aberd.,

Surgeon, Royal Spinal and Orthopaedic Hospital. Birmingham; Consulting Orthonaedic Surkeon. Ministry of Pensions.
West Midlunds Region.

Scccessful treatment of compound fractures demandss a thorough knowledge of the treatment of fractures by external splintage. Before the war the resuits of the operative and non-operative treatment of simple fractures was a subject of investigation by a special conmittee of this Association. In nearly every age.group operative cases showed a higher percentage of good results than non-operative cases. The suggestion to an unbiassed observer was that operative technique would in time almost entirely supplant treatment by. splintage.

I think you will agree that as a result of the war the outlook is changed. In the early days the compound fractures presented a problem which could not be solved by operation. The splints of the textboolss got a fair trial and were found wanting. The minds of the greatest surgeons of all countries were endeavouring to devise means for the fixation of the compound fracture of the lower extremity, and only after two years did it become 